\title{
PIEZAS DRAMÁTICAS INDIANAS \\ UN COLOQUIO POÉTICO A LA PURIFICACIÓNDE POTOSÍ (CONVENTO DE SANTA TERESA)
}

\section{Los textos dramáticos del convento de Santa Teresa de Potosí}

El convento de Santa Teresa de la Villa Imperial de Potosí ofrece al visitante un pulcro museo y una preciosa sección de libros y manuscritos, entre los que figura una caja con piezas dramáticas cortas, compuestas entre los siglos XVII y XIX, destinadas a las fiestas del Carmelo. Andrés Eichmann ${ }^{1}$ ha editado recientemente una de esas piezas, dando ya noticia de este corpus, que descubrimos en una excursión durante el III Encuentro Boliviano de Estudios Clásicos, celebrado en Sucre, en agosto de 2002, y que he descrito con más detalle en una ponencia ${ }^{2}$ leída en el Congreso "Temas del Barroco Hispánico”, organizado por el Grupo de Investigación Siglo de Oro (GRISO) y la Pontificia Universidad Católica de Valparaíso, en noviembre de 2003.

Debemos a la Madre Carmen, superiora del convento, las facilidades para estudiar estas piezas, de las que nos envió fotocopias. Los manuscritos muestran desigual estado de conservación y faltan partes enteras en algunas obras ${ }^{3}$. En general, no hay grandes desperfectos y las mayores dificultades provienen de los errores de copia o alteraciones en el orden de ciertos fragmentos en alguna pieza.

La colección, copiada por distintas manos y, sin duda, a lo largo de cierto tiempo, presenta, creo, un notable interés, pues refleja fielmente el tipo de textos que formaba parte de las celebraciones poto-

${ }^{1}$ Véase "El Coloquio de los Once Cielos. Una obra de teatro breve del Monasterio de Santa Teresa (Potosí)”, Historia y Cultura, La Paz, 2003, núms. 28/29, 95-132.

${ }^{2}$ Actualmente, en prensa, en las Actas del Congreso chileno que aparecerán en Iberoamericana. Los párrafos que siguen reproducen, con pocas variaciones, algunos otros de la citada ponencia. Pido una disculpa por las repeticiones, pero me parece necesario dar una somera noticia del contenido de la colección para tener una idea aproximada del Coloquio editado en este trabajo.

${ }^{3}$ Eludo ahora las descripciones de los manuscritos que nos ocuparán en el momento de la edición completa que estamos preparando. 
sinas (sobre todo en los ciclos de Navidad y la Candelaria), y supone un incremento en el número de piezas dramáticas conocidas, principalmente auriseculares, conservadas en Hispanoamérica. En especial, engrosa de manera notable el conjunto de materiales de la zona de Charcas.

Muy pocos datos tenemos del teatro del Siglo de Oro en Potosí: un artículo relativamente reciente de Maritza Wilde, dedicado a la "Presencia del Siglo de Oro en Potosí"4, no menciona detalles concretos ni maneja datos fehacientes sobre las representaciones; algunos comentarios acerca de la Tragedia de Atahualpa o la Diablada, o de autores como Diego Mejía de Fernangil y fray Juan de la Torre, es todo lo que ofrece. Eichmann ${ }^{5}$ ha puntualizado que

No hay que olvidar que el repertorio conocido de obras teatrales conservadas de Charcas no es muy abultado, a pesar de su intenso cultivo en las ciudades más importantes del territorio, es decir La Plata y Potosí. El teatro fue un "componente cotidiano de la vida potosina" 6 , atestiguado por muchas fuentes; además, "está claro y es conocido que La Plata y La Paz formaban circuito en las giras de las compañías teatrales por Charcas"7. Hay también ejemplos de teatro indígena en sitios más apartados como Oruro. Pero el paradero de muchas de las obras cuya representación consta en documentos y crónicas, es desconocido.

En este panorama, la colección de Santa Teresa puede considerarse un hallazgo de notable relevancia que incluye, por otro lado, algunas piezas de intrínseco valor literario. En varias obras se advierte, además, un sincretismo lingüístico (jerga de negros, quechua, espanol, latín macarrónico) y una adaptación de formas y personajes al ámbito indiano que procuraremos estudiar en su momento. La colección está compuesta de los siguientes textos: $a$ ) siete entremeses: El pleito de los pastores, Entremés dedicado a la Verdad, Entremés del astrólogo tunante, Entremés de los compadres (dos copias, una de ellas incompleta), Entremés de los tunantes, Entremés cantado del robo de las gallinas, Entremés gracioso para la festividad de Nuestra Señora de 1799; b) dos coloquios, seis loas y una denominada zarzuela. Todas estas piezas son de dimensión, estructura y técnica semejante, aunque ofrecen algunas variaciones curiosas. La mayoría está escrita para la fiesta de la Purificación o de la Candelaria. La que se titula Loa a la Asunción

${ }^{4}$ En América y el teatro español del Siglo de Oro. Actas del II Congreso Iberoamericano de Teatro, Universidad, Cádiz, 1998, pp. 281-287. Para otros aspectos del teatro español del Siglo de Oro en Hispanoamérica, que no me interesan ahora directamente, remito a este volumen.

${ }^{5}$ Art. cit., p. 96.

6 J. Barnadas, J. y A. Forenza, "Noticias sobre el teatro en Charcas (siglos XVIxIx)", Anuario 2000, Biblioteca y Archivo Nacionaes de Bolivia, Sucre, 2000, p. 558.

7 Ibid., p. 570. 
coincide en buena parte del texto con otra Loa dedicada a la Purificación de María Santísima. Dos loas son para el Nacimiento de Jesús. Destaca del conjunto la Loa de Nuestra Señora del Carmen, que es una exaltación de la orden carmelita a la que pertenece el convento, escenario de las representaciones; $c$ ) una serie de papeles sueltos y piezas incompletas: partes sueltas para una obra navideña, para el personaje de Iris, para la Obediencia, para un pastor, y otro fragmento musical. Hay fragmentos de dos comedias de tres jornadas (papeles de Enrica y santa Matilde, y papel de Margarita), y de dos piezas menores. Los papeles corresponden a los textos que un actor debía memorizar y tienen señalados los reclamos (palabras finales de los parlamentos anteriores), que dan pie para la entrada del parlamento de los personajes en cuestión. Alguna de estas piezas podría reconstruirse, en parte, reordenando en su lugar los parlamentos ${ }^{8}$.

Poco se puede decir sobre la datación de los textos. El convento se fundó en 1687, alguna de las piezas, como la Loa de Nuestra Señora del Carmen, debe haber sido escrita por una monja, para el ámbito conventual, y es sin duda posterior a la fundación. En la colección se incluye el Entremés gracioso, fechado en 1799 (¿fecha de escritura o de copia?); la Loa para el nacimiento del Niño Dios, escrita por el devoto Mariano Fernández, podemos situarla en la fecha que indica en el título, 1830.

La mayor parte de los textos pertenecen, por su estética, al Siglo de Oro, extendido en Hispanoamérica durante el siglo XVIII. De las autorías se pueden señalar tan pocos detalles como de las fechas. Algunos textos religiosos hay que atribuirlos a las monjas del convento que no consideraron necesario especificar sus nombres como autoras. Los copistas, igualmente sin identificar, son siempre locales, como evidencian fenómenos reflejados en las copias: seseo, ceceo, fenómenos fonéticos de influencia quechua, etc., muy perceptibles en el copista del Coloquio poético.

\section{Las piezas religiosas y el Coloquio pó́tico a la PURIFICACión}

Los textos religiosos ${ }^{9}$ pertenecen a dos ciclos principales que responden a los dos momentos de celebraciones en que se inserta su representación teatral: la Navidad y la fiesta de la Purificación o Virgen de la Candelaria.

${ }^{8} \mathrm{Al}$ parecer, se han perdido ciertas partes, como las de los personajes de la cocinera, el sacristán y la buñolera, cuya presencia denuncia el texto (aquí está la buñuele$r a$, etc.).

${ }^{9}$ Varios entremeses se sitúan también en la Navidad y la Candelaria. Se trata sin duda de adaptaciones a la ocasión concreta de las representaciones. 
Abre la serie la zarzuela, dedicada a la Purificación. Aunque se denomina zarzuela es una especie de loa de 285 versos, en su mayoría octosílabos, con alternancia de rima asonante y consonante y pasajes cantados con música y otros hablados. Los personajes son alegorías: el Placer, el Mundo, el Amor, el Regocijo, la Intercesión y la Alegría, y tiene por tema central los rituales de la fiesta de la Candelaria, como buena parte de estas composiciones ${ }^{10}$.

De la segunda pieza, el Coloquio de la Purificación de Nuestra Señora en que hablan los Once Cielos, ha hecho una edición anotada Eichmann ${ }^{11}$, quien también se ha ocupado de la organización alegórica de este debate en que los once cielos u orbes celestes defienden su preeminencia en los festejos de la Candelaria.

Cuatro piezas más se añaden a las dos anteriores sobre el tema de la Purificación. Una es el Coloquio poético a la Purificación, objeto de este trabajo; le sigue la Loa a la Purificación de María Santísima, cuyo texto principal es un diálogo entre el Ángel y el Hombre que desarrolla una rica simbología mariana (aurora, madre de la gracia, tálamo del Esposo, paraíso, torre de David, escala de Jacob, paloma, vara de Jesé, etc.). La Loa a la Asumpción de María Santísima no se distingue esencialmente de la anterior; de hecho, otra loa siguiente, que se titula Loa dedicada a la Purificación de María Santísima, coincide en su mayor parte con el texto de esta de la Asunción. Aunque se trata de dos fiestas diferentes, para ambas ocasiones pueden servir igualmente las loas mencionadas. Otras dos loas pertenecen al ciclo navideño, la Loa dedicada al nacimiento de Cristo y la Loa para el nacimiento del Niño Dios. Queda, por fin, una última loa específicamente destinada a la exaltación de la orden del Carmelo y la Virgen del Carmen, la Loa de Nuestra Señora del Carmen. Seis personajes organizados en parejas desarrollan esta pieza: los Montes Atlas y Carmelo, los profetas Elías y Eliseo, la Virgen y Santa Teresa.

El Coloquio poético a la Purificación de Nuestra Señora es una pieza de 242 versos, anónima, en la que dialogan Simeón, Ana, el ángel Gabriel, la Ley mosaica y Sorobabel, criado de Simeón, con ribetes de gracioso. El autor de la pieza es instruido, versado en la Biblia y con cierta propensión al uso de cultismos, de los que hay bastantes ejemplos significativos en el texto: armonía, inculca, oráculo, numen, plectro, enfático, purpúreo nácar, ostentando, púrpura, ufana, candores, cándida.

El copista debió ser indígena, a juzgar por algunos fenómenos fonéticos reflejados en las grafías. Los más llamativos son los de seseo (constante) y ceceo, las vacilaciones de timbres vocálicos $(\mathrm{i}=\mathrm{e}, \mathrm{o}=\mathrm{u})$, fenómenos de sonorización de velares, vacilaciones $1 / \mathrm{r}$, diptongacio-

10 Para esta pieza, remito a mi ed. y comentario que aparecerá en el Homenaje a Avalle-Arce (Universidad de Navarra, en prensa).

11 Art. cit., en este trabajo el autor ofrece más precisiones sobre este Coloquio. 
nes. He aquí algunos ejemplos de seseo: purificasión, Sorobabel, puresa, hase, suseso, crese, dulses, contradisión, voses, rasón, padese, veloses, notisia, dise, siego, asusena, alcansa, confiansa, presio; ceceo: curcio (curso), ancias (ansias); vacilaciones vocálicas: devina (divina), arribata (arrebata), altira (altera), alentarsi, nomen (numen), atrive (atreve), gimir, disi (dice), sirvir, equevalen, brutó (brotó), supirior, ejecuturia, brelle (brille), exeme (exime), egnorancia, acridita, colejo (colijo), suprimo (supremo); sonorización: degado (dejado), alendad (alentad); diptongaciones: aciento, priesto, hey (he), lueygo (luego), priendas; y otros fenómenos más escasos: ligor (rigor), ladiantes (radiantes).

En el tratamiento del texto modernizo las grafías que no tienen trascendencia fonética, pero ante la imposibilidad de delimitar qué rasgos se deben al copista y cuáles corresponden a la lengua del autor, mantengo las grafías que reflejan los fenómenos fonéticos mencionados.

Una cuestión relevante es la que afecta a las deturpaciones textuales y errores de copia. Generalmente propongo enmiendas, que sólo pueden ser tentativas y por el sentido apoyado en la rima, ya que el testimonio es único y no disponemos de otras fuentes textuales que suplan las lagunas o equivocaciones del manuscrito base. Ofrezco aquí algunos ejemplos, aunque lo hago con más exhaustividad en las notas al texto: ya en el título aparece la calificación de pocheo para el coloquio, que interpreto poético; en la lista de personas se copia mal perionas; en el v. 5, que duler melodia, sin duda es errata de copia por dulce melodia; Traculo sagrado (v. 25) reclama la enmienda a Oráculo; no entiendo, en el v. 42, santo cielo de el orad, que es, me parece, mala lectura por declarad; la lectura del manuscrito en el v. 46, puresa la rason padese, no hace sentido y produce un verso largo; enmiendo fuerza la razón padese, que cumple con todos los requisitos, etc. Véanse los casos de enmiendas en los vv. 52, 53, 62, 74, 87, etc. No he podido corregir satisfactoriamente algunos lugares. De todo queda noticia en el aparato de notas.

La estructura del Coloquio es sencilla. La Música celebra la práctica de la Purificación de la Virgen con dulces melodías que admiran a Simeón y Ana, quienes no acaban de comprender el enigma que encierra la pureza que se purifica. El ángel Gabriel orienta sus pasos hacia la escena - no representada-de los ritos piadosos que constituyen esta ceremonia, y que se supone presencian los personajes "dentro". Tras un breve interludio del gracioso Sorobabel, que se queja del hambre que su amo le hace pasar, regresan Ana y Simeón, edificados y gozosos por lo que han visto, confesando la maravilla del nacimiento del Mesías, flor de la vara de Jesé. Interviene entonces la Ley Vieja para expresar, en contraste, su incredulidad: si la Virgen ha realizado la ceremonia de la Purificación es que necesita purificarse, y por tanto no es la madre del Mesías. El ángel Gabriel explica 
a la Ley Escrita el sentido de lo que ignora: María ha cumplido los ritos no por obligación, sino por humildad ejemplar. El niño nacido es el Verbo divino que termina con la vigencia de la Ley Antigua, superándola en la nueva etapa de la Ley de la Gracia.

La Purificación de la Virgen es, pues, el tema central de esta pieza, como lo es en otras varias de la colección. Celebra uno de los episodios de la Sagrada Familia en que José y María se dirigen al templo de Jerusalén con Jesús para hacer las ofrendas prescritas en la ley de Moisés, leyes que toda madre que daba a luz a su primogénito debía cumplir para purificarse. El relato puede leerse en el evangelio de san Lucas, 2:22-39:

Cuando se cumplieron los días de la purificación de ellos, según la Ley de Moisés, llevaron a Jesús a Jerusalén para presentarle al Señor, como está escrito en la Ley del Señor: "Todo varón primogénito será consagrado al Señor" y para ofrecer en sacrificio un par de tórtolas o dos pichones, conforme a lo que se dice en la Ley del Señor. Y he aquí que había en Jerusalén un hombre llamado Simeón; este hombre era justo y piadoso, y esperaba la consolación de Israel; y estaba en él el Espíritu Santo. Le había sido revelado por el Espíritu Santo que no vería la muerte antes de haber visto al Cristo del Señor. Movido por el Espíritu, vino al Templo; y cuando los padres introdujeron al niño Jesús, para cumplir lo que la Ley prescribía sobre él, le tomó en brazos y bendijo a Dios diciendo: "Ahora, Señor, puedes, según tu palabra, dejar que tu siervo se vaya en paz; porque han visto mis ojos tu salvación, la que has preparado a la vista de todos los pueblos, luz para iluminar a los gentiles y gloria de tu pueblo Israel”. Su padre y su madre estaban admirados de lo que se decía de él. Simeón les bendijo y dijo a María, su madre: "Este está puesto para caída y elevación de muchos en Israel, y para ser señal de contradicción jy a ti misma una espada te atravesará el alma! a fin de que queden al descubierto las intenciones de muchos corazones”. Había también una profetisa, Ana, hija de Fanuel, de la tribu de Aser, de edad avanzada; después de casarse había vivido siete años con su marido, y permaneció viuda hasta los ochenta y cuatro años; no se apartaba del Templo, sirviendo a Dios noche y día en ayunos y oraciones. Como se presentase en aquella misma hora, alababa a Dios y hablaba del niño a todos los que esperaban la redención de Jerusalén. Así que cumplieron todas las cosas según la Ley del Señor, volvieron a Galilea, a su ciudad de Nazaret.

La Virgen no estaba realmente obligada a esta Purificación, innecesaria para su caso excepcional de concepción y parto virginales, pero cumple ejemplarmente con la ley. Así lo explica la pieza que edito:

Hoy la mesma puresa se purifica, que obedece al precepto que no le obliga 
lo mismo que otras de estas loas y coloquios potosinos dedicados al tema, como la zarzuela de la Purificación ${ }^{12}$ :
Lo más admirable es
ver una madre tan pura, más refulgente que el sol más hermosa que la luna, esenta de toda culpa, siempre intacta y siempre fiel que como tal no le obliga ni le comprende la ley. Solo por darnos ejemplo y enseñarnos la humildad desde Belén hasta el templo se parte a purificar (vv. 45-56).

A este propósito, Eichmann cita un texto de Ramos Gavilán que cumple aducir aquí:

Cristo y su Santísima Madre quisieron sujetarse a la ley para enseñarnos que la obediencia es la medicina verdadera para alcanzar la salud del alma. La desobediencia fue la puerta por donde entró el mal de nuestra miseria, y así Cristo, para que nos veamos libres de las manos de aquel Dragón infernal, nos enseña, juntamente con su Madre Santísima a obedecer y guardar la ley de Dios. Mostró la Virgen en aqueste hecho heroico actos profundísimos de humildad, pobreza y obediencia, y de singular devoción y reverencia, pidiendo al Sacerdote rogase a Dios por ella. Mostró juntamente grande amor a la pureza y limpieza, pues con estar limpia de toda culpa, gustó y quiso purificarse, para enseñarnos que el camino verdadero de agradar a Dios es el de la limpieza13.

En el Coloquio, el ángel Gabriel se encarga de aclarar, a la Ley Vieja, lo que ésta no comprende, es decir el verdadero sentido de la ceremonia y la humildad del acto.

La fiesta litúrgica de la Purificación, que constituye el ámbito de las celebraciones teatrales en las que se inserta el Coloquio que edito, se conoce también como la Candelaria, por el simbolismo de la procesión de las candelas y su bendición. A mediados del siglo v, esta

12 Véase mi artículo, "Teatro del Siglo de Oro en Indias. La «zarzuela» de la Purificación de Potosí (Convento de Santa Teresa)", en el Homenaje a Avalle-Arce, cit. supra, n. 10. Eichmann (art. cit.) aporta testimonios al respecto de diversas autoridades y padres de la Iglesia que enseñan la exención de la Virgen y su voluntad humilde de cumplir con la ley.

13 Historia del célebre santuario de Nuestra Señora de Copacabana, y sus milagros, e invención de la Cruz de Carabuco (Gerónimo de Contreras, Lima, 1621), Academia Boliviana de la Historia, La Paz, 1976, lib. 3, octavo día. 
fiesta se conocía como la Candelaria o Fiesta de las Luces. Hasta el siglo vi se celebraba a los cuarenta días de la Epifanía, el 15 de febrero; después, se fijó el 2 de febrero, a los cuarenta días de la Navidad, cuando la Virgen presentó a Jesús en el templo. De origen oriental, esta fiesta no se introdujo en la liturgia del Occidente hasta el siglo VII. Al final de este siglo ya estaba extendida en toda Roma y en casi todo Occidente.

Si bien la estructura, como he señalado, es sencilla, se percibe cierto grado de elaboración estilística. Los cultismos caracterizan el habla de personajes serios, como el ángel Gabriel o la Ley Vieja, pero se tiene cuidado de contraponer a ese registro el más vulgar del gracioso Sorobabel, según la doctrina del decoro dramático bien conocida en el Siglo de Oro: en el habla de Sorobabel se integran vulgarismos, refranes y expresiones coloquiales (hacer pucheros, un loco hace ciento, quedarse a la luna). El añadido del elemento cómico es también rasgo característico de las fórmulas dramáticas auriseculares: Sorobabel insiste en el motivo del hambre, típico de los graciosos, y parodia las intervenciones de Simeón y Ana (cf. vv. 124-129).

La Música desempeña un papel importante como signo del lenguaje divino, expresión de la armonía superior capaz de atraer antes al pecho que a los oídos materiales. El ingenio se explora también en diversas formas de agudeza, fundamentalmente en el enigma central (misterioso enigma, v. 43; enigma prodigioso, v. 51, etc.), que propone la paradoja de la pureza que se purifica, obedeciendo a un precepto que no la obliga. Otras modalidades son las alusiones mitológicas con simbolismo a lo divino (como la de Orfeo en el v. 32) y las bíblicas (la zarza de Moisés, la vara de Jesé, etc.). En estos casos se apunta a la técnica de la tipología, en la que episodios y personajes del Antiguo Testamento se interpretan alegóricamente como referencias al Nuevo.

En la breve extensión del Coloquio, la variedad métrica no es menos significativa de su empeño estético: aparte de fragmentos de métrica más irregular obedientes a la música (característica habitual en pasajes cantados), se hallan formas métricas como seguidillas, romances, octavas, pareados o silva de consonantes, la menos usual estrofa sexteto lira (vv. 111-129), y el romancillo hexasilábico.

Mientras terminamos la tarea de la edición completa del corpus del convento carmelita de Potosí, ofrezco en este trabajo la edición del Coloquio poético a la Purificación de Nuestra Señora como muestra de la categoría de textos que certifican una actividad teatral continua en la zona de Charcas, muy enraizada en los modelos del Siglo de Oro.

IgNACIO ARELLANO 


\section{COLOOUIO POÉTICO ${ }^{14}$ \\ A LA PURIFICASIÓN DE NUESTRA SEÑORA}

Personas $^{15}$

Simeón

El Ángel San Grabiel

Ana

La Ley Vieja ${ }^{16}$

Sorobabel, ministro ${ }^{17}$ de Simeón.

Música Hoy la mesma puresa

se purifica,

que obedece al precepto

que no le obliga.

Sale Simeón por una parte y Ana por otra.

Simeón ¿Qué dulce* melodía

percibe mi desvelo*,

que si hiere los oídos

con soberano imán violenta el pecho?

14 En el ms., pocheo.

15 El ms. dice Perionas.

16 Ley Vieja: o Ley Escrita, es la que va desde Moisés a Cristo, gobernada por el código de leyes explícitas del Pentateuco; en Dicc. Aut., "Ley escrita. Los preceptos que Dios Nuestro Señor dio a Moisés en el monte de Sinaí”. La historia teológica de la humanidad tiene tres etapas regidas por tres leyes, culmina en la tercera etapa o Ley de Gracia, que abarca desde Cristo hasta la consumación final regida por los nuevos preceptos de amor dados por Cristo y transmitidos por la Iglesia, el pueblo judío, anclado en la ley de los profetas, rechaza esta última. Las opiniones acerca de las tres edades no son uniformes. Por ejemplo, Hugo de SAN Víctor dice categóricamente que los hombres de la Ley Natural (los paganos) eran francamente malos; los de la Escrita (los judíos) eran buenos sólo en apariencia, y los de la Ley de Gracia (los cristianos) son realmente buenos (PL, t. 175, col. 32). Y san Agustín: "Para que los hombres no tratasen de obtener algo que les faltaba, se escribió en tablas lo que no leían en los corazones. Tenían escrita la ley, pero no querían leer... como los hombres, apeteciendo las cosas externas, se apartaron de sí mismos, se dio la Ley Escrita; no porque no estuviese escrita ya en los corazones, sino porque habiendo huido tú de tu corazón, debías ser acogido por aquel que está en todas partes" (Narraciones sobre los Salmos, en Obras de san Agustín, ed. B. Pérez, BAC, Madrid, 1966, sal. 57, 1, cit. por M. Peinado, La predicación del Evangelio en los Padres de la Iglesia, BAC, Madrid, 1992, núm. 291). Estas tres leyes son omnipresentes en los autos sacramentales de Calderón y en otros poetas. R. ARIAS estudia las tres leyes a propósito de un auto calderoniano (“Análisis de Los misterios de la misa, de Calderón”, RF, 94, 1982, 179-208).

17 Ministro, en el sentido de criado, servidor.

5. El ms. dice que duler, por descuido o error del copista.

6. En el ms., mi desdelo; enmiendo. 
ANA

¿Qué cadencia devina*

mi arribata el afecto,

el alma tras sé lleva*

con tan suave ligor que no le siento?*

Simeón Ana.

ANA Simeón.

Simeón ¿No escuchaste

aquel misterioso acento

de una vos que hase armonía

más que en el oído en el pecho?

Ana Ya percibe* su cadencia, y lo que resuena el eco

es un cuidado que inculca

novedad en el suseso.

SIMEón ¡Oh, cómo el alma se altira!

Ana ¡Oh, cómo crese el desvelo!

Simeón ¡Oh, si volviera a alentarsi!

Ana $\quad$ Oh, si repitiera el eco!

SIMEÓN Oráculo* sagrado

cuyo admirable aciento

hiere con lo que halaga, ¡vuelve, vuelve a alentar tus dulses ecos!

Ana Divino nomen sabio* cuyo armónico plectro

9. Nótense los fenómenos fonéticos que registra la grafía: alteración de timbres vocálicos (devina, arribata), cambio de alveolar vibrante a lateral (rigor =ligor), etc.; no los señalaré en todos los casos porque me parecen evidentes y no tienen mayor dificultad.

11. Seguramente quiere decir tras sí; señalo mi interpretación con el acento gráfico.

12. La música lo arrastra con fuerza, pero muy suave, de modo que no siente ese rigor como opresión, sino como gozo.

17. Parecería mejor percibo.

25. Por mala interpretación de su modelo, el copista escribió aquí Traculo sagrado.

29. Nomen: numen, divinidad. 
arribata el cuidado,

¡hiere, hiere la lira, sacro Orfeo!*

Música Dentro Hoy la misma puresa

se purifica;

pásmese el cielo,

que obedese al precepto

que no le obliga.

SimeÓN

¿Hoy la mesma puresa

se purifica"?

Parece contradisión

lo que las voses afirman*.

¡Santo cielo, declarad*

este misterioso enigma!

Ana ¿QQue obedese al precepto

que no le obliga"?

Fuerza la rasón padese*

en lo que el eco publica:

haz perceptible esta cifra*.

Sale el Ángel.

Ángel ¿ ¿Por qué os turba el cuidado el misterioso

enfático romor de mi armonía?

El que enigma os parese prodigioso

priesto a la pena formará alegría*

si enderesáis el curcio presuroso*

al templo santo donde en este día

la que es cuna del sol por ser su aurora*

32. Sacro Orfeo, recuérdese el auto de Calderón, El divino Orfeo, donde desarrolla abundantemente esta tipología mitológica a lo divino.

41. El ms. dice las [tachadura] dies afaman. Enmiendo reconstruyendo lo que me parece más probable, según otros pasajes del Coloquio.

42. En el ms., santo cielo de el orad, que es mala lectura; enmiendo según la solución que me parece evidente por el sentido.

46. El ms. lee puresa la rason, lo que hace largo el verso. Debe haber una mala lectura que corrijo, por ahora, como queda arriba.

48. Cifra: enigma.

52. El ms. dice a la pena le formara, que hace largo el verso. Enmiendo quitando el pronombre.

53. En el ms., preneroso. Curso presuroso es sintagma tópico que asegura bastante la corrección.

55. Cuna del sol, aurora: la Virgen. La metáfora de aurora para la Virgen es frecuente, lo mismo sucede con la del sol para Cristo. En De los nombres de Cristo, FRAY 


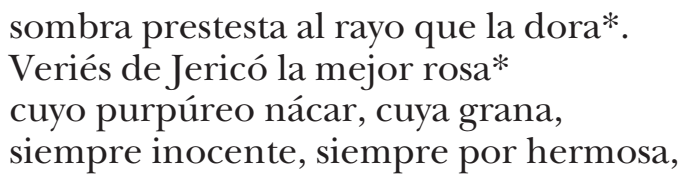

Luis comenta: "porque había comparado al aurora el vientre de la madre y porque en el aurora cae el rocío con que se fecunda la tierra, prosiguiendo en su semejanza, a la virtud de la generación llamóla rocío también. Y a la verdad así es llamada en las divinas letras, en otros muchos lugares, esta virtud vivífica y generativa con que engendró Dios al principio el cuerpo de Cristo y con que después de muerto le reengendró y resuscitó" (ed. C. Cuevas, Cátedra, Madrid, 1984, p. 189). El significado de iluminación, dado a la imagen del sol como símbolo de Cristo que libera al hombre de las tinieblas del pecado, tiene en la tradición cristiana amplia representación. Por ejemplo, Ruperto ABAD llama a Cristo sol de justicia, nacido de María, que ilumina el mundo entero: "Quis enim est iste sol, nisi sol iustitiae Christus, sol verus et aeternus, qui in ista die, in isto tempore mundum universum illuminavit, et quando coepit iste dies luminis, nisi quando visitavit nos oriens ex alto sol iste, quem miro modo Maria, id est maris stella peperit?” (PL, t. 168, col. 361). AlAIN DE LiLle comenta el mismo simbolismo, a partir del texto de Isaías, 62:1, "non quiescam, donec egradiatur ut splendor iustus eius, et salvatur eius ut lampas accendatur". Se trata, dice, de la venida de Cristo, el justo, del que procede la justicia de la Iglesia y que surge como esplendor por su naturaleza humana y divina: "Christus dicitur antonomastice Ecclesiae Justus... Qui ut splendor dicitur egredi secundum utramque naturam" ( $P L$, t. 210, col. 232). Comentario similar se encuentra en S. Fulgencio, que toma como punto de partida el texto de Lucas, 1:78-79, "visitavit nos oriens ex alto, illuminare his qui in tenebris et in umbra mortis sedent" (PL, t. 65, col. 544); o SAN AgusTín: "dies magni solis modo celebramus: illius solis de quo dicit Scriptura: Orietur vobis sol iustitiae, et sanitas in pennis eius (Mal, 4, 2)" ("celebramos ahora los días del gran sol, aquel del que dice la Escritura: Amanecerá para vosotros el sol de justicia y en sus alas trae la salvación', Sermones, en Obras, BAC, Madrid, 1981-85, sermón 68, 7); 75, 5; 78, 2: "Dominus ipse Iesus resplenduit sicut sol... Ipse Iesus quidem, ipse splenduit sicut sol, se lumen esse significans quod illuminat omnem hominem venientem in hunc mundum"; $25 \mathrm{~A}, 1$. Para no alargar más esta nota con infinitos lugares remito a C. A LAPIDE, quien comenta con abundancia de detalles distintos sentidos y matices simbólicos del sol: símbolo de Dios (Commentarii... R. P. Cornelii a Lapide, Ludovicum Vives, Paris, 1878, V, 117, 1; XVII, 328, 2; XIX, 352, 1, 2); imagen de la voluntad divina (XXI, 37, 1); símbolo de la divinidad y Dios de justicia (X, 29, 1); símbolo de Cristo (X, 390, 1; XVIII, 224, 2); el sol naciente simboliza a Cristo (XIV, 389, 1, 2); sol de justicia es Cristo en su primera venida, por varias analogías (XIV, 606, 2); sol refulgente es Cristo (XXI, 35, 2; 36, 1); sol naciente y sol poniente son símbolos de Cristo (XVII, 48, 2); también símbolo de la Virgen (X, 12, 1; 391, 1), y de la Iglesia (XX, 436, 1 ss.: importante sentido para el pasaje del Mundo en nuestro auto); expresa a los santos y los justos (X, 31, 1); a los sacerdotes (XV, 155, 1); a la verdad, caridad, virtudes (VII, 37, 2; X, 391, 1; VII, 498, 1), etc. En fin, véase la síntesis de FRAY LUIS DE GRANADA: "tales son las propriedades y excelencias desta estrella, que con no ser las criaturas, como dicen, más que una pequeña sombra o huella del Criador... todavía entre las criaturas corporales, la que más representa la hermosura y omnipotencia del Criador en muchas cosas, es el sol" (Introducción del Símbolo de la $F e$, ed. J. M. Balcells, Cátedra, Madrid, 1989, p. 197).

56. Sombra pretesta, como si el sol (Jesucristo) tuviese alguna sombra necesaria de limpiar con los ritos religiosos, aunque no tiene ninguna. Es un cumplimiento respetuoso de la Ley Antigua, como ejemplo de humildad y piedad.

57. Rosa de Jericó, la rosa es la reina de las flores, de suavísimo olor, y las de Jericó 
no ostentando matices ponga vana,

sí ocultando la púrpura honorosa, entre espinas costodia bien la grana*

de una hermosura que a sí mesma debe*

haser pinta al lunar que no se atrive.

Simeón Alada inteligencia, ya que toca*, sigue el alma tus voses.

$\mathrm{Va}[\mathrm{se}]$.

Ana Ya tu dulce armonía ingeniosa sigo en pasos veloses.

Vas[e].

Sale Sorobabel.

Sorobabel Señores ¿no me darán notisias de un santo viejo que dise espera la vida solo por quedarse muerto? Los días y las noches gasta en llorar con tales gestos* que yo descurro a la muerte escondida por no verlo tal gimir, tal suspirar, y disi que todo esto es porque vean sus ojos de todo el mundo el remedio.

Mas yo tengo que el vejete como a la inocencia ha vuelto porque le den lo que pide

gozaban de fama particular: "Rosa est regina florum... haec odoris est suavissimi... Talis est sapientia, nimirum purissima, odoratissima et sapidissima... Jam, quod comparat sapientiam rosae in Jericho, significat Jerichuntis rosas fuisse excellentiores caeteris, sive specie et rubore, sive odore... sive magnitudine" (C. A LAPIDE, op. cit., IX, 637-640). Cf. P. Calderón de la BarCa, La lepra de Constantino: "de rosas que en Jericó” (Obras completas, t. 3: Autos, ed. A. Valbuena Prat, Aguilar, Madrid, 1987, p. 1800); y La cena de Baltasar: "Pues cuando él de la flor de Jericó" (ibid., p. 165).

62. Verso corto en el original, bien grana. Añado el artículo para regularizar la métrica, pero nótese que repite la palabra en rima (grana). Quizá haya una deturpación textual mayor.

63 No entiendo este pasaje; debe haber alguna deturpación.

65. Así, en el ms. No entiendo el pasaje.

74. En el ms., gustos, pero la rima y el sentido apoyan la enmienda. Los siguientes vv. (75-76) me parecen confusos. 
como niño hase pucheros.

Lo peor es, cual como dicen

un loco suele haser siento*, a mí me han vuelto* muchacho

pues ya paga estoy pidiendo*, porque es tanta su miseria

en ministrarme el sustento

que de solo no comer

juru a Dios que ya me muero.

No hay cosa peor que sirvir

a viejos chochos y güeros*

que cren también que ayunemos*.

Buscándolo estoy perdido*

y pardiés que si lo encuentro

sigún estoy siego de hambre

me lo hey de comer entero.

Suena dentro música.

Música En brazos del aurora

divino* sol se mece:

él le presta esplendores*

y ella luses le bebe;

por quedar con el sol

priendas la aurora ofrese*,

priendas que no equevalen

al lustre que le deben.

86. Un loco suele haser siento es un refrán conocido: "Un loco hará ciento"; o "un loco hace ciento" (G. CoRREAs, Vocabulario de refranes y frases proverbiales, CD-ROM, ed. digital R. Zafra, GRISO-Reichenberger, Pamplona-Kassel, 2000, refrán 23048).

87. En el ms. dice vello.

88. Paga es un juego de palabras: los niños piden la paga o propina a los mayores, pero Sorobabel reclama que le paguen un salario mejor.

94. Güero: "Lo que está vacío o tiene dentro cosa inútil y sin sustancia. Díjose propiamente del huevo corrompido y de que no sale pollo" (Dicc. Aut.). El esquema de la rima denuncia la falta de algún verso en este lugar del romance.

95. En el ms., cren; no sé si interpretar como alusión a las creencias del viejo Simeón, en cuya religión, según Sorobabel, entraría también la creencia en el ayuno; o si será alteración del texto y habrá que leer 'quieren que ayunemos'.

96. En el ms., esty perdido.

101. El ms. dice disino.

102. En el ms., quelendores.

105. Priendas: los levitas (tribu de Leví) se destinaban al sacerdocio, y todo primogénito que perteneciera a las demás tribus era primero ofrecido a Yavé, y luego "rescatado" a cambio de cinco siclos de plata (Números, 18:15-16); además, era necesario ofrecer un cordero en holocausto de adoración. También estaba escrito que si la familia era pobre (era el caso de María y José) podían ofrecer una tórtola o paloma (Levítico, 12:8). 
Sorobabel ¡Oh, qui bien hace esta aurora!

No largue al sol, que aquello

de quedarse a la luna*

no le ha de haser provecho.

Suena dentro música y sale Simeón y Ana.

Simeón Ya, Señor, que mis ojos

su salud soberana ver lograron*, ya que los rayos rojos*

de tu devina lus se revelaron,

pues ver más no deseo

acábese mi vida en lo que veo.

AnA Ya que logra, Señor,

sus ancias satisfechas el desvelo,

pues* de Giesé la flor

brutó en la vara que fundó el cielo, si no busco más gloria, acábese mi aliento en su memoria.

Sorobabel Ya que tu providencia

consuela a todos, ten, Señor, piedad*

de mi grave indigencia

pues padesco tan cruel necesidad

que se gunta la flaquesa*, tengo desvanesida mi cabesa.

110. Quedarse a la luna hace alusión a otro refrán conocido, como "Quedarse a la luna de Valencia", sin conseguir lo pretendido, frustrado.

113. Dice el ms.: lograr.

114. En el ms., rayos ojos.

120. El ms. dice puse; flor de Giesé: Jesucristo. La vara de Jesé es el árbol genealógico de Cristo: "Et egredietur virga de radice Iesse, Et flos de radice eius ascendet" (Isaías, 11:1). Esta profecía, según la cual el Mesías saldría de la familia de Jesé, padre de David, se cumple en la genealogía con que abre el evangelio de Mateo (1:6-16), en la que José, esposo de María, de la que nace Jesús, procede, en última instancia, de los descendientes de David. Del pasaje de Isaías, la patrística interpreta vástago (virga) como Virgen (virgo), y retoño ( flos) como Cristo (san Bernardo Abad de Claraval, Obras, ed. R. P. Germán Prado, $B A C$, Madrid, 1947, p. 528, texto latino en PL, t. 183, col. 63). En la iconografía medieval, por ejemplo, en la vidriera de Jesé, de la catedral de Chartres, se visualiza esta profecía en un árbol, que sale de Jesé, y en cuyas ramas aparecen cuatro reyes de Judá, posiblemente David, Salomón, Roboam y Abiá (tomados de la lista de Mateo, 1:6-7), después María (no José, como en el Evangelio), y en lo alto del árbol, Cristo. Véase I. Arellano, Diccionario de los autos sacramentales de Calderón, Universidad de Navarra-Reichenberger, Pamplona-Kassel, 2000.

125. Verso largo en el ms.: tened Señor piedad; el tratamiento de tú en el verso anterior apoya la enmienda.

128. No veo claro este verso, pero no hallo corrección segura. 
Sale la Ley.

LEY ¿Qué voses alentáis mal entendidas?, que según lo que infiere mi cuidado las leyes no halagáis* obedesidas de quienes a la ley se han sujetado. ¿Condisiones que son establesidas para purgar la mancha que ha degado* la impuresa del parto ha de buscar la madre que se exeme del lunar*? ¿Acaso los preceptos supiriores obligan a los númenes sagrados? ¿Necesitan de aliño los candores* de la bella asusena de los prados? Luego vuestros contentos son errores, vanos consuelos, júbilos sanados* de quien sabe lo que quiere mas no alcansa* lo que solo le finge la confiansa.

Sale el Ángel.

Ángel No prosigas errada, ¡oh, tú, cadente ley, mal informada!, que agravia a todo el cielo ese ignorante envanecido velo*. Esa madre que ofrese al infante más bello no obedese, que supone la acsión pareser obediente sujeción y siendo independiente humilde se acridita, no obediente. ¿Acaso se obscurese el nácar de la aurora porque mece

132. En el ms., hagais. Me parece mejor la enmienda.

135. Así, en el ms. Mantengo el reflejo gráfico del fenómeno fonético.

137. Lunar corregido sobre lugar. La argumentación de la Ley Antigua es la siguiente: si la Virgen cumple con los ritos de Purificación es porque los necesita, por tanto se entiende que no es la madre del Mesías, si lo fuera, no necesitaría cumplir con esos ritos.

140. En el ms., cantores, pero creo que es error de copia y no fenómeno fonético; la blancura o candor de las azucenas no necesita adorno.

143. El ms. dice unos consuelos, que no parece hacer buen sentido.

144. Verso largo; no entiendo bien este pasaje. Además, lee de quien sebe lo que.

149. Velo puede ser imagen de la ignorancia o alusión al vestuario de la representación. Me inclino a pensar, sin embargo, que la buena lectura sería celo, pues la Ley Vieja muestra celo excesivo y mal informado porque no comprende los hechos. 
al sol que en arreboles ostenta en cada rayo muchos soles?

Antes queda la aurora

ufana con la gala que le dora*,

que el sol no desfigura

cuando añade esplendor a la hermusura.

Pues ¿cómo tú, ignorante,

cuando al sol de justicia en ese infante*

debes ya contemplar

a la madre atribuyes el lunar*?,

pues [es] ejecutoria*

que acredita el motivo de su gloria

lo que tu sinrasón

en ella te adjudica sujesión.

LEY Sagrada deidad, no culpes

mi egnorancia en lo que afirmo*;

se hay misterios en lo oculto*

yo no alcanzo su sentido.

Si esa madre y esa prole

mis preseptos* han cumplido,

aunque no asierte no yerro

si el dominio me adjudico.

¿Quién juzgará que la rayes*

de Jeesí ya ha florecido

en esa mujer que busca

ejecuturia a lo limpio,

y quien creerá que su flor

se exeme de mi dominio

cuando rescata lo libre

al presio de mi albedrío?

161. En el ms., pana con la gala o para con la gala; creo que hay un error de copia y enmiendo por el sentido.

165. Sol de justicia: sintagma aplicado a Cristo, como se ha visto en los testimonios de simbolismo solar cristológico en una nota anterior.

167. El ms. dice atribuyes el lusero, que sin duda es error de copia, pues no rima ni tiene sentido. Lo que la Ley Vieja atribuye a la madre es una mancha que debe purificarse, sin comprender que no puede tener lunar ninguno la madre del sol de justicia.

168. Suplo es, que ha omitido el copista, confundido al escribir esecutoria y enmendar luego executoria, olvidando la forma verbal. rrección.

173. El ms. dice afirmes, pero la rima del romance y el sentido aconsejan la co-

174. En el ms., que se ay, lo que hace largo el verso. Se es modificación fonética del si condicional. Otra enmienda posible es leer misterio en singular para permitir la sinalefa: que si hay misterio en lo oculto.

177. El ms. dice presepto.

180. Así, en el ms.: 'raíz' (vara de Jesé, según he anotado ya). 
Luego si el hijo y la madre*

me obedesen, bien colejo

que aun está en flor la esperansa

porque el fruto no ha nasido.

Ángel Sin duda que a tu notisia

el misterio se ha escondido

pues duda tu senrasón

aunque la obedencia ha visto.

$¿$ No le acuerda que el fuego a la espinosa

verde zarza* vistió de resplandores

sin que aun a sus verdores

sufocase* la llama misteriosa,

milagro supirior

que brelle lus lo que aun no es ardor?

Esa que veneraste maravilla

esenta zarza al pesar del fuego

copia es sagrada de la que ven tus ojos*

fingiendo sus candores

de la llama voray fieros despojos*, cuando son sus ladiantes esplendores cándida su fin el lavar de sombra*, pues la llama que en ella se amplifica* no tenía, no, el candor que purifica.

Lueygo si es en la verdad esa mujer exepción,

188. El ms. dice si el hiyla Madre.

197. En el ms., verdenaria, enmiendo por lo pronto. Con respecto a zarza, Dios se aparece a Moisés en forma de zarza ardiendo que no se consume y manda que libere a los israelitas de Egipto (Éxodo, 3:2). La exégesis bíblica ve en Moisés la figura de Cristo (san Isidoro, $P L$, t. 83, col. 109; Hugo DE S. Víctor, PL, t. 177, cols. 492493); la zarza ardiendo se interpreta como anuncio mesiánico. Cf. P. CALDERÓN DE LA BARCA, La vacante general: "sin que antiguas circunstancias / de tus noticias me toquen / en la visión de la zarza. / _¿Por qué? - Porque su prodigio / sobre otras señales varias / del prometido Mesías... / Como en ella [la zarza] hallo / dos cosas, contra mí entrambas; / una el ser zarza, que es / tan débil, e inútil rama, / ... / y otra, el que en divina llama, / sin deshacerse ilumine, / y sin consumirse arda: / ¿fuego, que vive, y no quema; / fuego, que alumbra y no abrasa, / no dice divino ser? / ¿Fuego de caridad, planta / tan humilde, que quizá / Dios por humilde la ensalza, / no dice humana criatura, / que exenta y privilegiada / del común riesgo de todos, / solamente ella se salva?" (en Obras completas, ed. cit, t. 3, p. 1161). Consúltese, también, Diccionario de los autos de Calderón, cit. supra, n. al v. 120.

199. En el ms., suforase.

204. Verso largo.

206. Voray: voraz.

208. Así, en el ms. Debe haber alguna deturpación porque el pasaje es algo confuso, aunque la idea general quede clara.

209. En el ms. dice seaplica, corregido luego en seaplifica. 
no la traye su obligasión*, sí la obliga humildad.

LeY Pues ya que mi fin cumplido contemplo mi antiguo* dominio rendiré al despecho*.

Vas[e].

Ángel Vosotros que ves al devino* Verbo en carne pasible* como niño tierno, desplegad los labios y en júbilo alterno alendad el goso

al calor del pecho: siguid la armonía que comiensa el cielo dándole el honor al numen suprimo.

Vanse todos y queda solo [Sorobabel].

Sorobabel Grasias a mi Dios

que ya mi buen* viejo vio lo que deseaba.

Con esto ya espero que cuide mejor

de sus buenos secreos*

y yo no andaré

con el vientre hueco,

$Y$ vio otras madres

flores del Carmelo*:

perdonad al poeta

que solo es de afecto.

213. Verso hipérmetro.

217. En el ms., mi antio ominio.

218. En el ms., si rendia al despecho.

220. El ms. dice desino.

221. En el ms., carne posible, creo que se trata de un error simplificador de la lectura buena.

232. El ms. dice bien.

236. Así, secreos, en el ms. No se me ocurre una buena solución.

240. Del Carmelo: recuérdese que esta pieza está destinada a las representaciones en el convento de Santa Teresa, en la villa de Potosí, de monjas carmelitas. 